\title{
Leaders
}

\section{Snowboarding injuries}

Since the inception of the idea of riding a board on the snow in the 1970s, the popularity of the winter sport of snowboarding has burgeoned. Snowboarding is the only area of the winter sports market that has continued to grow. The 1994-1995 NSAA Kottke National Business Survey indicated that $14 \%$ of the 54 million area visits in the United States were generated by snowboarders. ${ }^{1}$ It has been reported that $80 \%$ of children who participate in snow sports have ridden snowboards by their 12th birthday. ${ }^{2}$ Industry analysts project that by the early 2000 s more than $40 \%$ of those on the slopes will be snowboarders.

With the rise in popularity of snowboarding there has been a change in the injury pattern of these winter sports participants as compared with skiing. There has also been the recognition of an ankle injury that is specific to and only occurs in snowboarding. Along with a number of other medical facilities in Colorado, our clinic participated in a 10 year survey of snowboarding injuries (1988-1999). A total of 7430 snowboarding related injuries were seen in 7051 patients; $74.1 \%$ of those injured were male and $25.9 \%$ were female. Of the injured snowboarders, $45.2 \%$ were beginners, $31.4 \%$ intermediate, and $23.4 \%$ expert. There were significantly more upper extremity injuries than with skiing, which accounted for $49.1 \%$ of all injuries.

Ankle injuries accounted for $12 \%$ of all injuries, and fractures of the lateral process of the talus fractures accounted for 3\%. Lateral process fractures, or snowboard- er's talus fractures, are problematic and continue to be underdiagnosed and under-reported. Any acute and/or persistent anterolateral ankle pain in a snowboarder should be considered a talus fracture until proven otherwise. Most of these fractures are not able to be diagnosed by plain radiographs and require computed tomography imaging for definitive diagnosis. Most snowboarder's talus fractures need operative treatment with excision of fracture fragments or internal fixation of the fractures.

With the continued growth of snowboarding it will be increasingly more important for practitioners to be familiar with the diagnosis and treatment of snowboarding injuries. The studies have resulted in identifying and defining of a spectrum of injuries different from those of alpine skiing. Now that the spectrum of snowboarding injuries has been identified, the challenge will not only be the appropriate treatment of such injuries but also education about, research into, and prevention of such injuries. This will not only be the responsibility of the health care provider but also that of manufacturers, ski area owners and developers, snowboard shops, as well as snowboarders themselves.

THOMAS P MOORE

Rocky Mountain Sports Medicine and Orthopedic Clinic, Crested Butte and Basalt, Colorado, USA

\footnotetext{
SnowSports Industries America National Snowboarder Survey. McLean, Virginia: SnowSports Industries America, 1995 and 1996.

2 Meyers C. On the edge: new riders on the Olympic stage. Ski Magazine 1996;25:25
}

One of the best pieces of public health news in recent years has been that you do not have to be a marathon runner, sports champion, or even regular jogger to derive substantial health benefits through exercise: regular moderate physical activity has cardioprotective and other health benefits. ${ }^{1}$ From this and our low levels of exercise as a population, it can reasonably be concluded that promoting regular moderate physical activity - active living - is not only the most feasible route for exercise promotion but also the one that will yield the largest population health gain. $^{2}$

HEBS (the Health Education Board for Scotland) has been something of a pioneer of the active living approach in the United Kingdom. ${ }^{2-4}$ We place a strong emphasis on walking because of its accessibility. Walking is easy for most people to contemplate and do, regardless of age or fitness level. It does not require special skills, expensive equipment, or facilities. It can be built into everyday lifefor example, in commuting, shopping, and leisure. And the risk of injury is generally low. ${ }^{5}$ HEBS commissioned qualitative research conducted in 1995 supported this notion of accessibility, with preference being shown for walking over swimming or dancing. The same research, however, suggested that walking was not generally viewed as "real" exercise, there being a belief that to be beneficial exercise has to make people sweaty and out of breath. Also, there were negative "non-aspirational" perceptions of walking, including (older) age profile, low status as a form of transport, and a boring image. Further developmental research pointed to the value of giving people "surprising" information about the value of walking.

A few years on, if you ask people what they think of when they hear of "HEBS", their answer will probably include the name "Gavin". They are referring to the TV advertising campaign that arose from the developmental research. Paradoxically using a sporting hero to promote regular moderate activity, the advertisement features Gavin Hastings comparing walking a mile with energy equivalent amounts of vigorous exercise. He points out that "you don't have to" take part in sweaty, frenetic, or very demanding forms of exercise to gain health and fitness benefits; in essence you can walk to good health. In the first phase of running the advert on TV, it was backed up by a special telephone helpline offering a pack containing the HEBS self help guide Hassle free exercise and information on local level physical activity facilities and contacts. 
Formal evaluation of the first phase of the campaign is reported in detail elsewhere. ${ }^{6}$ Campaign awareness and walking related knowledge and beliefs were monitored through adult population surveys. Self reported changes in physical activity levels were assessed through a panel study involving a sample (initially 700) drawn from the 4036 people who had called the helpline during its first six weeks. A composite measure of "stage of change" (precontemplation, contemplation, preparation, action, maintenance) was derived from information provided by helpline callers at baseline and follow up. ${ }^{7}$ The rate of successful follow up at one year in the panel study was $58 \%$. The sociodemographic profile of respondents at one year was similar to that at baseline, except for a slightly higher attrition rate for younger people.

Campaign awareness was highest in the primary target group (socioeconomic groups C2DE). There was before/ after evidence of an impact on the general adult population's knowledge and beliefs about walking as a form of exercise, the biggest increase being in knowledge of exercise equivalence information specific to the campaign. This is evidence of success of the major campaign objective of "repositioning" walking in the minds of the public. Also, in the panel study there was a discernible shift in stage of change (in the right direction) between baseline and follow up. Furthermore, $48 \%$ of the helpline callers successfully contacted at one year reported being more active.

The panel study of helpline callers was of course potentially open to initial self selection bias, and to subsequent drop out and "desire to please" bias. Suppose for the sake of argument that almost 2000 people (48\% of 4036) were motivated and helped to become more active through the advertisement and helpline. Even in the absence of any such effect on people who viewed the advert but did not call the helpline - and disregarding the important informing and agenda setting roles of the campaign - this would be a worthwhile outcome and indeed would represent good value for money. However, this amount of behavioural change would not be detectable even in a fairly substantial survey of the general population.
In evaluation we therefore need to tap into "captive populations" (such as helpline callers) where they exist, and to manage potential bias through study design and analysis.

In any case, Gavin, with repeated showings, has undoubtedly caught the attention of the people of Scotland. Awareness of the advertisement in the adult general population runs consistently at around $90 \%$, and I have referred to its centrality to people's awareness of HEBS. In 1997 Gavin was voted favourite advertisement in a readers' poll conducted by The Scottish Sun as part of the Scottish Advertising Awards. This is no mean feat, and its significance in evaluation terms should not be underestimated. It is evidence that health education advertising can have a wide appeal and become part of the fabric of the nation, more than holding its own with more expensive and less socially useful advertising.

The campaign and other health education efforts - in schools, through the workplace and health service, and in other settings - are of course but pieces in a jigsaw of factors affecting the nation's levels of activity. Policies and action in areas such as community safety, transport, pollution control, urban and rural planning, and access to facilities are needed to make it more appealing and more feasible for people to build physical activity into their everyday lives at all stages and ages.

ANDREW TANNAHILL

Chief Executive, Health Education Board for Scotland

Woodburn House, Canaan Lane

Edinburgh EH10 4SG, Scotland

1 Pate RR, Pratt M, Blair SN, et al. Physical activity and public health: a recommendation from the Centers for Disease Control and Prevention and the American College of Sports Medicine. FAMA 1995;273:402-7.

2 Wimbush E. A moderate approach to promoting physical activity: the evidence and implications. Health Education fournal 1994;53:322-36.

3 HEBS. Promoting physical activity in Scotland: a policy statement. Edinburgh: Health Education Board for Scotland, 1995.

4 HEBS. The promotion of physical activity in Scotland: a strategic statement. HEBS. The promotion of physical activity in Scotland: a

Davison RCR, Grant S. Is walking sufficient exercise for health? Sports Med 1993;16:369-73.

1993;16:369-73. Wimbush E, MacGregor A, Fraser E. The impacts of a national mass
campaign on walking. Health Promotion International 1998;13:45-53.

7 Buxton K, Wyse J, Mercer T. How applicable is the stage of change mode to exercise behaviour? A review. Health Education fournal 1996;55:239-57.

\section{Role of exercise counselling in health promotion}

Despite the clear health benefits that can be attained through adopting a more active lifestyle, most adults in the United Kingdom as well as other industrial nations remain underactive. Faced with this epidemic, there is a growing need for physical activity interventions that can be widely disseminated to all segments of the population across the lifespan.

One promising avenue for physical activity counselling and support lies with the primary care doctor and other health care professionals. The strengths of incorporating physical activity advice and support as part of routine health care include the ability to reach a substantial portion of the population repeatedly over time, the consistency and continuity of message content and delivery, and the willingness among patients to act on their doctor's advice. ${ }^{12}$ Despite these strengths, however, a number of barriers to physical activity counselling in primary care have been documented, including lack of time, reimbursement, and training in physical activity or behaviour change counselling. ${ }^{3}$ Although such barriers present continuing challenges to the health promotion and health care fields, the potential public health impact that primary care settings can have on health behaviour change, including physical activity, merits continued investigation.

Although a relatively large body of research exists on advice and counselling by doctors for other health behaviours, such as smoking, relatively little systematic research has been conducted to date on physical activity promotion in primary care. The studies that have been undertaken have taken advantage of a growing body of knowledge, underscoring the utility of applying empirically supported behavioural strategies in facilitating physical activity change. Such behavioural strategies, derived primarily from social cognitive theory and its derivatives, include: identifying specific practical physical activity goals tailored to the patient's needs and circumstances; structuring initial patient expectations so that they are realistic; identifying those benefits related to becoming more physically active that are most germane to the patient's own health status; encouraging the patient to keep track of his or her own physical activity patterns through simple self 
monitoring tools; and providing continual interest, encouragement, and support for physical activity. Some of these behavioural strategies have been used in studies in which primary care doctors have been trained to deliver brief advice and counselling on physical activity, with encouraging results in the short term. ${ }^{45}$ In one study, for example, a written goal oriented exercise prescription from general practitioners, in addition to verbal advice, was particularly effective in promoting increased physical activity over a six week period. ${ }^{6}$ More discrepant results obtained from longer term multiple risk factor programmes, however, suggest that more intensive interventions may be needed to obtain longer term effects in at least some segments of the population. Such interventions could include the use of health educators and professionals in addition to the doctor. Health educators and other allied health professionals can provide a level of advice and counselling beyond that which doctors, constrained by time and similar barriers, are typically able to deliver. ${ }^{7}$ One promising approach awaiting more extensive investigation involves using brief advice from the doctor as a means of setting the stage for physical activity change in conjunction with specific referral to other health care based or community based health educators or providers. In this way, the perceived credibility and authority of the doctor can be harnessed as a catalyst for change, while the very real time constraints facing many doctors are recognised. ${ }^{8}$ The challenge remains to structure the referral network effectively such that patients will successfully follow through with the referral. To maximise the potential benefits of this type of referral network, continuing communication between the doctor and referral source is essential.

In addition, the studies targeting primary care providers have focused almost exclusively on doctors involved in family practice and internal medicine. Yet, other primary care specialties, such as paediatrics and obstetricsgynaecology, reach important segments of the population for whom physical activity information and messages are particularly relevant. Future research should target the full range of primary care practice.

While face to face instruction and counselling for physical activity have traditionally been the norm in most countries, a growing scientific literature has underscored the utility of mediated channels for delivering physical activity advice and information in an efficient, effective, and potentially less costly fashion. For instance, in the United States, at least 13 randomised controlled investigations have systematically evaluated the use of telephone based physical activity advice and support, either in conjunction with or independent of advice from the doctor. ${ }^{7910}$ The telephone supervised physical activity approach has been shown to be effective in both older and younger adult populations, women as well as men, cardiac patients, older family carers of relatives with dementia, and overweight patients. It has been found to be effective in promoting physical activity of various types - for example, endurance, strength, flexibility, general conditioning-intensities-for example, moderate intensity exercise, more vigorous exercise - and formats - for example, home based, group based, combinations of home based and group based exercise. Telephone and similar mediated approaches allow both the health professional and the patient a level of convenience and flexibility that is often diminished or lacking in group based physical activity regimens.

In summary, to reach the public health goals on physical activity in the United Kingdom, United States, Australia, and other countries continued efforts to involve primary care providers and other health professionals as active facilitators of the physical activity message are strongly indicated. Primary care advice in conjunction with referral to appropriate community organisations may help to facilitate the long term increases in physical activity participation that are critical for health promotion and disease prevention. Telephone and other mediated approaches to physical activity promotion provide a promising avenue for programme delivery, in primary care as well as other community settings.

Stanford University School of Medicine

ABBY C KING

Palo Alto

CA 94304-1583, USA

1 Williford HN, Barfield BR, Lazenby RB, et al. A survey of physicians' attitudes and practices related to exercise promotion. Prev Med 1992;21:630-6.

2 Goldstein MG, DePue J, Kazura A, et al. Models for provider-patient ineraction: applications to health behavior. In: Shumaker SA, Schron SB, Ockene JK, et al, eds. The handbook of health behavior change, 2nd ed. New Yckene JK, et al, eds. The handbor

3 Pender NH, Sallis JF, Long BJ, et al. Health care provider counseling to promote physical activity. In: Dishman RK, ed. Exercise adherence, 2nd ed. mote physical activity. In: Dishman RK, ed. Exer
Champaign, IL: Human Kinetics, 1994:213-35.

4 Calfas KJ, Long BJ, Sallis JF, et al. A controlled trial of physician counseling to promote the adoption of physical activity. Prev Med 1996;25:225-33.

5 Marcus BH, Goldstein MG, Jette A, et al. Training physicians to conduct physical activity counseling. Prev Med 1997;26:382-8.

6 Swinburn BA, Walter LG, Arroll B, et al. The green prescription study: a randomized controlled trial of written exercise advice provided by general practitioners. Am F Public Health 1998;88:288-91.

7 King AC, Sallis JF, Dunn AL, et al. Overview of the activity counseling trial (ACT) intervention for promoting physical activity in primary care settings. Med Sci Sports Exerc 1998;30:1086-96.

8 Stevens W, Hillsdon M, Thorogood M, et al. The cost effectiveness of a primary care-based physical activity intervention in $45-74$ year old men and women: a randomised controlled trial. Br f Sports Med 1998;32:23641 .

9 DeBusk RF, Haskell WL, Miller NH, et al. Medically directed at-home rehabilitation soon after clinically uncomplicated acute myocardial rehabilitation soon after clinically uncomplicated acute myocar
infarction: a new model for patient care. Am $\mathcal{f}$ Cardiol 1985;55:251-7.

10 King AC, Rejeski WJ, Buchner DM. Physical activity interventions targeting older adults: a critical review and recommendations. Am f Prev Med 1998; 15:316-33.
Traditional dogma would have it that pain in tendinopathy arises through one of two mechanisms. Firstly, it may result from inflammation in "tendinitis". Secondly, it may be due to separation of collagen fibres in more severe forms of tendinopathy. The latter situation parallels the mechanism of pain with collagen separation after an acute grade I or II ligament injury (fig 1).

Despite the wide acceptance of these two classical models of pain production, a number of studies provide data inconsistent with either theory. Consider first the inflammation mechanism. Histopathological examination of surgical specimens from patients with chronic tendon pain are devoid of inflammatory cells. ${ }^{1}$ This applies to tissue from the Achilles, patellar, lateral elbow, medial elbow, and rotator cuff tendons. Furthermore, prostaglandin E2 (a marker of the inflammatory process) is no more abundant in patients with Achilles tendon pain than in normal controls. ${ }^{2}$ 
Unfortunately, the collagen separation theory does not hold up under scrutiny either. The following five observations about pain and collagen in the patellar tendon are inexplicable. (a) Patients who have patellar tendon allograft anterior cruciate ligament reconstruction have minimal donor site knee pain, yet collagen has been excised. (b) Such patients are generally pain-free (and back at sport) despite the persistence of abnormal collagen for two or more years. ${ }^{34}$ (c) Similarly, after open surgery for jumper's knee, the imaging appearance of the tendon-that is, collagen status-does not correlate consistently with knee pain. ${ }^{5}$ (d) Patients with jumper's knee can also be treated by an arthroscopic debridement of the infrapatellar fat pad and the posterior border of the patellar tendon without operation on the collagen defect in the tendon itself. ${ }^{6}(e)$ Large asymptomatic ultrasonographic hypoechoic regions (abnormal collagen) can be found in patellar tendons of some athletes who have never had a history of jumper's knee. $^{78}$

Such discrepancy between collagen structure and pain is not confined to the patellar tendon. Patients with partial (non-perforated) rotator cuff tears were found to have more pain than those with complete perforations ${ }^{9}$ despite the former having less collagen damage. Clearly there is more to tendon pain than discontinuity of collagen per se.

Nociceptors provide significant afferent pain pathways. In the knee, they are located in the retinaculum, fat pad, synovium, and periosteum, ${ }^{10}$ and all these structures may play a role in the tendon pain pathway. Biochemical irritants may include extravasation of glycosamines, especially chondroitin sulphate, ${ }^{112}$ from damaged tendon.

The five observations listed above can be explained with what we term a "biochemical" hypothesis (fig 2). We speculate that the pain of patellar tendinopathy is largely due to biochemical agents irritating nociceptors located in the fat pad immediately posterior to the patellar tendon. In 39 cadaver dissections of the proximal patellar tendon, ${ }^{13}$ we consistently identified a thin layer of fat adherent to the posterior portion of the patellar tendon. In the corresponding tissue specimens from patients operated on for chronic

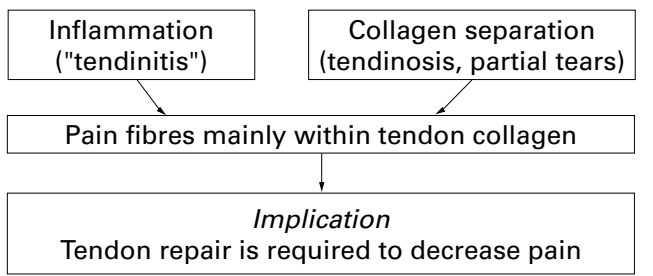

Figure 1 The classical "inflammatory" and "structural" tendon pain models. jumper's knee, this fat tissue contained increased Alcian blue stain (and thus glycosaminoglycans), presumably leaked from the adjacent region of tendinosis.

To our knowledge, the key irritant biochemical agent has not yet been identified, and this presents a challenge for tendon biochemists. Using microdialysis, Alfredson recently identified an abnormal amount of the excitatory neurotransmitter, glutamate, in subjects with painful Achilles tendinopathy. ${ }^{2}$ Until these histopathological and biochemical findings are correlated with some measure of pain, we can only speculate as to whether they are causative, or merely byproducts of nearby tendinosis.

Of interest, in the rotator cuff pain and pathology study quoted above, ${ }^{9}$ collagen damage was inversely related to pain, but the presence of substance $\mathrm{P}$ (a nociceptive neurotransmitter) was significantly associated with pain. Nerve fibres immunoreactive to substance $\mathrm{P}$ were localised around vessels in the subacromial bursa and in the non-perforated rotator cuff. ${ }^{9}$

Although the data presented may suggest a biochemical cause of pain, other workers consider mechanical impingement of the fat pad as a cause of anterior knee pain. The Australian physiotherapist, Jenny McConnell, recognised fat pad impingement as a cause of anterior knee pain (not necessarily tendon pain) over 10 years ago. Johnson proposed that impingement caused the pain of patellar tendinopathy. ${ }^{14}$ The infrapatellar fat pad is an extremely sensitive region ${ }^{15}$ and contains a large number of nociceptors, but as tendon pain occurs at many anatomical sites, it does not appear logical that a structure related to only one tendon - that is, the patellar fat padwould necessarily play a unique role in a problem as widespread as tendinopathy. Further, the clinical observation that the pain of jumper's knee does not disappear and may actually increase when palpation is performed with the knee in full extension would appear to argue more for a biochemical than a mechanical cause of pain in tendinopathy. Nevertheless, the jury requires more evidence.

If our biochemical hypothesis proves to have some validity, it would have significant clinical and research implications. In clinical management, the aim of treatment would be to modify the biochemical milieu, rather than to focus on reducing inflammation or necessarily augmenting collagen repair. Collagen repair may, of course, improve the biochemical milieu and thus explain why eccentric strengthening programmes can help. ${ }^{16}$ Researchers would be encouraged to pursue a pharmaceutical approach focused on reducing the irritant (but not necessarily inflammatory) biochemical compounds around the tendon. Surgery may play a role through denervation. Thus, if sports medicine researchers collaborate with basic scientists who understand pain physiology, knowledge will be

\begin{tabular}{|l|}
\hline $\begin{array}{c}\text { As yet unidentified biochemical noxious compounds (candidates include } \\
\text { matrix substances such as chondroitin sulphate) }\end{array}$ \\
\hline $\begin{array}{c}\text { Significant pain fibres in surrounding synovium and tissues, } \\
\text { as well as in tendon substance }\end{array}$ \\
Implications \\
$\begin{array}{c}\text { 1. Tendon repair is one method to decrease biochemical toxins and } \\
\text { thus pain }\end{array}$ \\
$\begin{array}{c}\text { 2. Pharmaceutical antidote to biochemical toxins would decrease pain } \\
\text { 3. Denervation of nociceptors - that is, certain surgery-would decrease } \\
\text { pain }\end{array}$ \\
\hline
\end{tabular}

Figure 2 Contemporary "biochemical" tendon pain model. 
advanced in both fields, and we will progress toward the goal of alleviating the pain of what is often structurally rather a trivial problem.

K M KHAN

School of Human Kinetics and Allan McGavin Sports Medicine Centre University of British Columbia

Vancouver, Canada

J L COOK

Victorian Institute of Sport Tendon Study Group and Alphington Sports Medicine Clinic, Melbourne, Australia

N MAFFULLI

Department of Orthopaedics

University of Aberdeen

Aberdeen, Scotland

P KANNUS

UKK Institute, Tampere, Finland

1 Khan KM, Cook JL, Bonar F, et al. Histopathology of common overuse tendon conditions: update and implications for clinical management. Sports Med 1999;27:393-408.

2 Alfredson H. In situ microdialysis in tendon tissue: high levels of glutamate, but not prostaglandin $\mathrm{E}_{2}$ in chronic achilles tendon pain. Knee Surg Sports Traumatol Arthrosc 1999;7:378-81.

3 Adriani E, Mariani PP, Maresca G, et al. Healing of the patellar tendon after harvesting of its mid-third for anterior cruciate ligament reconstruction and evolution of the unclosed donor site defect. Knee Surg Sports Traumatol Arthrosc 1995;3:138-43.

4 Kiss ZS, Kellaway D, Cook J, et al. Postoperative patellar tendon healing: an ultrasound study. Australas Radiol 1998;42:28-32.
5 Khan KM, Visentini PJ, Kiss ZS, et al. Correlation of US and MR imaging with clinical outcome after open patellar tenotomy: prospective and retrospective studies. Clin F Sport Med 1999;9:129-37.

6 Coleman BD, Khan KM, Kiss ZS, et al. Outcomes of open and arthroscopic patellar tenotomy for chronic patellar tendinopathy: a retrospective study. Am $\mathcal{F}$ Sports Med 2000;28:183-90.

7 Cook JL, Khan KM, Harcourt PR, et al. Patellar tendon ultrasonography in asymptomatic active athletes reveals hypoechoic regions: a study of 320 tendons. Clin 7 Sport Med 1998;8:73-7.

8 Lian O, Holen KJ, Engebrestson L, et al. Relationship between symptoms of jumper's knee and the ultrasound characteristics of the patellar tendon among high level male volleyball players. Scand 7 Med Sci Sports 1996;6:291-6

9 Gotoh M, Hamada K, Yamakawa H, et al. Increased substance P in subacromial bursa and shoulder pain in rotator cuff diseases. F Orthop Res 1998; 16:618-21.

10 Witonski D, Wagrowska-Danielewicz M. Distribution of substance-P nerve fibres in the knee joint in patients with anterior knee pain syndrome. A preliminary report. Knee Surg Sports Traumatol Arthrosc 1999;7:177-83.

11 Benazzo F, Stennardo G, Valli M. Achilles and patellar tendinopathies in athletes: pathogenesis and surgical treatment. Bull Hosp ft Dis 1996;54: 236-40.

12 Józsa L, Kannus P. Human tendons. Champaign, IL: Human Kinetics, 1997: 576.

13 Khan KM, Bonar F, Desmond PM, et al. Patellar tendinosis (jumper's knee): findings at histopathologic examination, US and MR imaging. Radiology 1996;200:821-7.

14 Johnson DP. Magnetic resonance imaging of patellar tendonitis. 7 Bone foint Surg [Br] 1996;78:452-7.

15 Dye SF, Vaupel GL, Dye CC. Conscious neurosensory mapping of the internal structures of the human knee without intra-articular anesthesia. Am $\mathcal{F}$ Sports Med 1998;26:773-7.

16 Alfredson H, Pietila T, Jonsson P, et al. Heavy-load eccentric calf muscle training for the treatment of chronic Achilles tendinosis. Am f Sports Med 1998;26:360-6.

\section{$\dot{\mathrm{V}}_{2}$ slow component and performance in endurance sports}

For almost 80 years, physiological studies have attempted to explain endurance performance and to develop ways of improving it by training. Performance for a runner can be represented by the relation of his/her personal power (velocity) to time to exhaustion (time limit). ${ }^{1}$

There are particular velocities that delineate intensity domains which are determined by oxygen uptake $\left(\mathrm{V}_{2}\right)$ and blood lactate response versus time. ${ }^{23}$ We are going to use them to define the slow phase of $\dot{\mathrm{V}}_{2}$ kinetics $\dot{\mathrm{V}}_{2}$ slow component) which only appears during intense exercise.

A high range of work can be identified at which there is a sustained increase in blood lactate and a decrease in arterial $\mathrm{pH}$ with time. These responses decline back towards a baseline value. Oxygen uptake increases in a monoexponential way and stabilises at about $80 \%$ in high level marathon runners for at least an hour and a half of continuous exercise. After that time, it is possible for oxygen consumption to increase because of thermoregulatory constraints, and this increase is called the " $\mathrm{VO}_{2}$ drift". This intensity of exercise corresponds to the velocity that can be sustained during a marathon and is equal to about $80 \%$ of the velocity associated with $\dot{\mathrm{V}}_{2} \mathrm{MAX}$ determined in an incremental test-that is, $\mathrm{v}_{\mathrm{VO}_{2}} \mathrm{MAX}^{4}$ During this type of exercise both lipids and carbohydrate are used as fuel.

At a higher intensity, the maximal lactate steady state occurs $^{5}$ when the rate of appearance of blood lactate equals the rate of its disappearance. $\dot{\mathrm{V}} \mathrm{O}_{2}$ stabilises after three minutes at about $85 \% \dot{\mathrm{VO}}_{2} \mathrm{MAX}$. This corresponds to the highest velocity that an athlete can sustain for an hour $(85 \%$ $\mathrm{v}_{\mathrm{O}_{2}} \mathrm{MAX}$ for a well trained endurance athlete); carbohydrate (and lactate even) is the main substrate for this exercise.

At a higher intensity, at about $90 \% \mathrm{v} \dot{\mathrm{VO}}_{2} \mathrm{MAX}$, the rate of appearance of blood lactate exceeds the rate of disappearance and therefore blood lactate increases. After the first monoexponential increase in $\dot{\mathrm{V}}_{2}$, there is a second increase after about three minutes which is defined as the $\dot{\mathrm{V}}_{2}$ slow component. $\dot{\mathrm{V}}_{2}$ reaches a delayed steady state which is higher than the $\mathrm{VO}_{2}$ requirement estimated from the relation between $\dot{\mathrm{V}}_{2}$ and moderate work rate. For instance, in this case the athlete can run at $90 \% \mathrm{vV}_{\mathrm{O}_{2}} \mathrm{MAX}$ and reaches and stabilises at $95 \% \dot{\mathrm{V}}_{2} \mathrm{MAX}$ at the sixth minute of exercise (time to exhaustion at this velocity being about 10-15 minutes). This corresponds to the so called "critical power" which is the vertical asymptote of the hyperbolic relation between power (velocity) and time. ${ }^{6}$ Time limit at the critical velocity is reduced to less than 30 minutes because of rapid glycogen depletion. ${ }^{78}$ The critical velocity is the highest velocity below its maximal level $\left(\dot{\mathrm{V}}_{2} \mathrm{MAX}\right)$ at which oxygen consumption can reach a steady state.

Above this critical velocity, during high intensity exercise, neither $\dot{\mathrm{V}}_{2}$ nor blood lactate can be stabilised, and both rise inexorably until fatigue ensues, at which point $\dot{\mathrm{V}}_{2}$ reaches its maximum value. ${ }^{9}$

The initial very small component (phase 1), resulting from a sudden change in the venous return in combination with a small change in the mixed venous gas tension, is not fitted into the following equation. In fact, the parameters for the oxygen uptake kinetics were obtained from a two component exponential model in which the first component accounted for the fast component (phase 2) and the second component accounted for the slow component (phase 3). The oxygen uptake kinetics are described as a function of time by the following equation ${ }^{10}: \dot{\mathrm{V}}_{2}(\mathrm{t})=\mathrm{A}_{0}$ (baseline) $+\mathrm{A}_{1}\left(1-\mathrm{e}_{1}^{-(\mathrm{tTD}) / \tau}\right)$ (fast component) $+\mathrm{A}_{2}$ $\left(1-\mathrm{e}^{-(\mathrm{tTD}) / \tau}{ }_{2}\right)$ ] (slow component)

where $A_{0}$ is the resting baseline value, $A_{1}$ and $A_{2}$ are the amplitudes for the two components, $\tau_{1}$ and $\tau_{2}$ are the time constants for the two components, and $\mathrm{TD}_{1}$ and $\mathrm{TD}_{2}$ are the time delays from the onset of exercise for the two components. 
Hence, the so called $\dot{\mathrm{V}}_{2}$ slow component is the second amplitude $\left(\mathrm{A}_{2}\right)$ of the increase in $\dot{\mathrm{V}}_{2}$ that appears at $\mathrm{TD}_{2}$. This second amplitude represents about $10 \%$ of the first $\left(A_{1}\right)$ and depends on the absolute intensity of exercise because $\dot{\mathrm{V}}_{2}$ is regulated by the split of ATP and phosphocreatine. ${ }^{11}$ The value of the $\mathrm{V}_{2}$ slow component can reach $500 \mathrm{ml} / \mathrm{min}$ and is generally considered to be significant when the value is above $200 \mathrm{ml} / \mathrm{min}$. To avoid the use of this complicated equation which necessitates the use of software such as Sigma plot (SPSS), the $\dot{V}_{\mathrm{O}_{2}}$ slow component can be identified as described initially by Whipp and Wasserman ${ }^{12}$ by calculating the difference in $\dot{\mathrm{V}}_{2}$ measurement between the 6th and 3rd minute or, if the exercise is performed until exhaustion, between the third and last minute. ${ }^{13}$

The appearance of this slow $\dot{\mathrm{V}}_{2}$ component is mainly due to the recruitment of fast fibre type II fibres with fatigue. ${ }^{14}$ It has been shown that type II fibres have a phosphate to oxygen ratio that is $18 \%$ lower than in type I fibres, probably because of a greater reliance on the $\alpha$-glycerophosphate shuttle than the malate-aspartate shuttle. ${ }^{15}$ Therefore more oxygen is required to produce the same level of ATP turnover and sustain a given power output. The other $15 \%$ is due to an increase in cardiac and ventilation work. Training decreases the $\dot{\mathrm{VO}}_{2}$ slow component at the same absolute velocity, mainly because of an increase in the distribution of type I fibres and an increase in mitochondrial and capillary density. ${ }^{16}{ }^{17} \mathrm{~A}$ decrease in the $\dot{\mathrm{V}}_{2}$ slow component can also appear for the same relative velocity (in \% $\mathrm{v} \dot{\mathrm{O}}_{2} \mathrm{MAX}$ ) because of an increase in the maximal lactate steady state. ${ }^{18}$ However, during intense exercise, the amplitude of the $\dot{\mathrm{V}}_{2}$ slow component is not linked to endurance at all. Moreover, it has been reported that triathletes that had no $\dot{\mathrm{V}}_{2}$ slow component in running compared with cycling had the same endurance time in these two types of exercise (at $90 \%$ of the power or velocity associated with $\dot{\mathrm{VO}}_{2} \mathrm{MAX}$ ). These triathletes also had the same maximal lactate steady state at $82 \%$ of velocity or power associated with $\dot{\mathrm{V}}_{2} \mathrm{MAX}$ in running and cycling.

Endurance training decreases the $\dot{\mathrm{V}}_{2}$ slow component at the same velocity. ${ }^{19-22}$ Personal data on high intensity training have shown that the decrease in the $\dot{\mathrm{V}}_{2}$ slow component at the same absolute intensity $(90 \%$ $\left.\mathrm{v}_{\mathrm{V}} \mathrm{O}_{2} \mathrm{MAX}\right)$ is not correlated with an improvement in performance (endurance time) at this velocity ( $+40 \%$ of time limit).

A more interesting fact about this $\dot{\mathrm{V}}_{2}$ slow component phenomenon is for training at $\dot{\mathrm{V}}_{2} \mathrm{MAX}$ as it creates a broad range of exercise intensities for which $\dot{\mathrm{V}}_{2} \mathrm{MAX}$ will occur, provided that the exercise is continued to the point of exhaustion. ${ }^{9}$

Hence, it may be possible to describe a new relation between time spent at $\dot{\mathrm{V}}_{2} \mathrm{MAX}$ (tlim $\left.\dot{\mathrm{V}}_{2} \mathrm{MAX}\right)$ and velocity as a percentage of the velocity associated with $\dot{\mathrm{V}}_{2} \mathrm{MAX}$ determined in an incremental test ( $\left.\mathrm{v} \dot{\mathrm{V}}_{2} \mathrm{MAX}\right)$. The relation between time to exhaustion at $\mathrm{VO}_{2} \mathrm{MAX}$ and velocity follows a function that has a peak around $100 \% \mathrm{vV} \dot{\mathrm{O}}_{2} \mathrm{MAX}$ in well trained runners who have no, or only a low value for, the $\dot{\mathrm{V}}_{2}$ slow component $(<200$ $\mathrm{ml} / \mathrm{min})$. In less well trained subjects, the $\dot{\mathrm{V}}_{2}$ slow component means that they spend longer sustaining $\dot{\mathrm{V}}_{\mathrm{O}_{2}} \mathrm{MAX}$ at $90 \% \mathrm{v} \dot{\mathrm{V}}_{2} \mathrm{MAX}$ than at $100 \% \mathrm{v}_{\mathrm{V}} \mathrm{O}_{2} \mathrm{MAX}^{23}{ }^{25} 26$ However, fit endurance athletes have to run at close to $100 \%$ of $\mathrm{v} \dot{\mathrm{V}} \mathrm{O}_{2}$ MAX to elicit $\dot{\mathrm{V}} \mathrm{O}_{2} \mathrm{MAX}$ because they have no $\dot{\mathrm{V}} \mathrm{O}_{2}$ slow component. ${ }^{2324}$

Therefore, in training, if the aim is to elicit $\dot{\mathrm{V}}_{2} \mathrm{MAX}$, it may be useful to determine the velocity for which time spent at $\dot{\mathrm{V}}_{2} \mathrm{MAX}$ is maximal. ${ }^{25}$ To determine at which velocity the longest time at $\dot{\mathrm{VO}}_{2} \mathrm{MAX}$ is obtained during con- tinuous exercise, the critical velocity at $\dot{\mathrm{V}}_{2} \mathrm{MAX}$ can be determined using the critical power model. Instead of total time limit run, only the time run at $\dot{\mathrm{V}}_{2} \mathrm{MAX}$ is plotted against the distance run at $\dot{\mathrm{V}}_{2} \mathrm{MAX}$. The slope of this plot is the critical velocity at $\dot{\mathrm{V}}_{2} \mathrm{MAX}$. This relation between tlim $\dot{V}_{\mathrm{O}_{2} \mathrm{MAX}}$ and velocity can be used to determine the velocity that elicits the longest time to exhaustion at $\dot{\mathrm{V}}_{\mathrm{O}_{2}} \mathrm{MAX}^{26}{ }^{27}$ This velocity is not significantly different from $\mathrm{v} \dot{\mathrm{V}}_{2}$ MAX determined from an incremental protocol, but is significantly higher than the critical velocity classically determined using a two parameter critical power model and the total distance-time. ${ }^{26}$

The existence of this $\dot{\mathrm{V}}_{2}$ slow component phenomenon raises the question of how athletes can adapt their training to improve performance. In fit runners, who are not at a high level $\left(\mathrm{v} \dot{\mathrm{V}} \mathrm{O}_{2} \mathrm{MAX}=19 \mathrm{~km} / \mathrm{h}\right)$, eight weeks of training at high intensity was shown to remove the $\dot{\mathrm{V}}_{2}$ slow component at the same absolute velocity (V Billat, A Demarle, J Slawinski and JP Koralsztein, unpublished work). This was because $\mathrm{v} \dot{\mathrm{V}} \mathrm{O}_{2} \mathrm{MAX}$ increased, and at the same velocity was at a lower percentage of $\mathrm{v} \dot{\mathrm{O}}_{2} \mathrm{MAX}$ than before training. The time limit at this previously high intensity training was doubled (20 v 10 minutes). At the same relative velocity to $\mathrm{v}_{\mathrm{O}_{2} \mathrm{MAX}}$, the $\dot{\mathrm{V}}_{2}$ slow component was comparable with that before training, which means that this high intensity training (twice a week) has to be calibrated at least every two months in this case.

In conclusion, the $\dot{\mathrm{V}}_{2}$ slow component phenomenon, which was first described by Margaria et al in the sixties ${ }^{28}$ and then by Whipp and Wasserman in the seventies, ${ }^{12}$ has been widely focused on in the nineties. In the light of this, it should be possible in the next five years to use the knowledge to diversify training and to explore endurance training effects and fitness.

VÉRONIQUE L BILLAT

University Lille 2, Centre de médecine du sport CCAS

75010 Paris, France

1 Billat V, Koralsztein JP, Morton H. Time in human endurance models. From empirical to physiological models. Sports Med 1999;27:359-79.

2 Whipp, BJ. The slow component of $\mathrm{O}_{2}$ uptake kinetics during heavy exercise. Med Sci Sports Exerc 1994;26:1319-26.

3 Whipp BJ, Ozyener F. The kinetics of exertional oxygen uptake: Whipp BJ, Ozyener F. The kinetics of exertional

4 Billat V, Koralsztein JP. Significance of the velocity at $\dot{\mathrm{VO}}_{2}$ max and its time to exhaustion at this velocity. Sports Med 1996;22:90-108.

to exhaustion at this velocity. Sports Med 1996;22:90-108.
Brooks GA. Anaerobic threshold: review of the concept and direction for Brooks GA. Anaerobic threshold: review of the conce
future research. Med Sci Sports Exerc 1985;17:31-5.

6 Monod H, Scherrer J. The work capacity of synergy muscular groups. Ergonomics 1965;8:329-38.

7 Housh DJ, Housh TJ, Bauge SM. The accuracy of critical power test for predicting time to exhaustion during cycle ergometry. Ergonomics 1989;32: 997-1004

8 Jenkins DG, Quigley BM. The Y-intercept of the critical power function as a measure of anaerobic work capacity. Ergonomics 1991;34:13-22.

9 Gaesser GA, Poole DC. The slow component of oxygen uptake kinetics in humans. In: Holloszy JO, ed. Exercise sport science review. Baltimore: Williams \& Wilkins, 1996:35-70.

10 Barstow TJ, Molé PA. Linear and nonlinear characteristics of oxygen uptake kinetics during heavy exercise. F Appl Physiol 1991;71:2099-106.

11 Walsh ML. Possible mechanisms of oxygen uptake kinetics. Annals of Physiological Anthropology 1992;11:215-23.

12 Whipp BJ, Wasserman K. Oxygen uptake kinetics for various intensities of constant-load work. I Appl Physiol 1972;33:351-6.

13 Billat V, Richard R, Binsse VM, et al. $\dot{\mathrm{VO}}_{2}$ slow component for a severe exercise depends on type of exercise and is not correlated with time to fatigue. f Appl Physiol 1998;85:2118-24.

14 Poole DC, Schaffartzik W, Knight DR, et al. Contribution of exercising legs to the slow component of oxygen uptake kinetics in humans. $\mathcal{F}$ Appl Physiol 1991;71:1245-53.

15 Willis WT, Jackman MR. Mitochondrial function during heavy exercise. Med Sci Sports Exerc 1994;26:1347-54.

16 Holloszy JO, Coyle EF. Adaptation of skeletal muscle to endurance exercise and their metabolic consequences. F Appl Physiol 1984;56:831-8.

17 Hoppeler H. Exercise-induced ultrastructural changes in skeletal muscle. Int 7 Sports Med 1986;7:187-204.

18 Yoshida T, Udo M, Ohmori T, et al. Day-to-day changes in oxygen uptake kinetics at the onset of exercise during strenuous endurance training. Eur $\mathcal{F}$ Appl Physiol 1992;64:78-83.

19 Berry M, Moritani T. The effects of various training intensities on the kinetics of oxygen consumption. F Sports Med Phys Fitness 1996;22:90-108.

20 Casaburi R, Storer TW, Ben-Dov I, et al. Effect of endurance training on possible determinants of $\mathrm{VO}_{2}$ during heavy exercise. $f$ Appl Physiol 1987;62:1533-8. 
21 Gaesser GA. Influence of endurance training and catecholamines on exercise $\mathrm{VO}_{2}$ response. Med Sci Sports Exerc 1994;26:1341-6.

22 Womack CJ, Davis SE, Blumer JL th al. Slow $1994 ; 26: 1341$ - 6 . ing heavy exercise: adaptation to endurance training. If Appl Physiol 1995;79:838-45.

23 Billat V, Binsse V, Petit B, et al. High level runners are able to maintain a $\dot{\mathrm{VO}}$ steady state below $\mathrm{VO}_{2 \max }$ in an all-out run over their critical velocity. Arch Physiol Biochem 1998;106:38-45.

24 Jacobsen DJ, Coast R, Donnelly JE. The effect of exercise intensity on the slow component of $\mathrm{VO}_{2}$ in persons of different fitness levels. F Sports Med Phys Fitness 1998;38:124-31.
25 Billat V, Slawinski J, Bocquet V, et al. Intermittent runs at $\dot{\mathrm{V}} \mathrm{O}_{2 \text { max }}$ enables subjects to remain at $\dot{V} \mathrm{O}_{2 \max }$ for a longer time than severe submaximal run.

26 Billat V, Blondel N, Berthoin S. Determination of the velocity associated with the longest time to exhaustion at maximal oxygen uptake. Eur $\mathcal{F} A p p l$ Physiol 1999;80:159-61.

27 di Prampero PE. The concept of critical velocity: a brief analysis. Eur F Appl Physiol 1999;80:162-4

28 Margaria R, Mangili F, Cuttica F, et al. The kinetics of the oxygen consumption at the onset of muscular exercise in man. Ergonomics 1965;8: 49-54.

\section{Should nasal fractures be treated on the spot?}

We all know the scenario at the side of the rugby pitch, as the team attendant or doctor yanks a nose straight before any pain is perceived by a front row "beauty" who then returns to play. But should nasal fractures be treated in this way, on the spot?

Would sports medicine doctors let their own broken noses be treated on the spot? "Yes, I'd have it put back pitch side-once I've retaliated and before the pain starts." "Depends who by."

"Yes I'd like it put back immediately . . .but I've had my nose put back on the field several times and then had to have a surgeon sort it all out later, but that's OK." (Personal discussions at the BASM 1999 conference)

What are the dangers of this procedure? If looks are spoilt, an athlete may be persuaded to sue who ever tampered with their nose and make the culprit pay for their private plastic surgery and loss of modelling career. Worse still would be the scenario of an underlying cribriform plate fracture (and possible other complications) being further disrupted by incompetent attempts at nasal fracture reduction or uncontrollable bleeding of the nose pitch side and miles from help.

Some questions before letting the doc sort the nose

Is the heat and pressure of the sports field the place to be deciding the severity of the fracture even if you are a doctor?

How much ENT training has the average sports doctor had?

Would an ENT surgeon reduce a fracture pitch side?

Would an ENT surgeon be happy for doctors, physiotherapists, or first aiders to reduce a nasal fracture "on the spot"?

ENT surgeons' opinions varied among those I contacted.

"Allowing a GP colleague, if experienced, or ENT surgeon to put their nose back pitch side. But not a 'bag man' pitch side or a casualty SHO (even after an $x$ ray) to do the same procedure."

"Bleeding following repositioning is unpredictable and it should be done in a hospital environment by an ENT colleague."

"Yes I would let an ENT colleague, GP or first aid/bag man put my nose back pitch side as I don't think $x$ rays are necessary for nasal fractures." (Personal correspondence with ENT surgeons in Scotland)

The Defence Unions referred to the Bolam Defence of "accepted practice" for a sports doctor. "If a member were to treat a displaced nasal fracture on the spot, and there was an unsatisfactory outcome, it may well be alleged that it was negligent to undertake such a procedure. In defending a member we would need to take into account the training and experience of the member and an independent expert opinion from a practitioner in the same speciality." (Personal correspondence with The St Paul International Insurance Agency).

"Advocates of an on the spot treatment of nasal fractures would have to show good supporting evidence that the outcome is at least as good, if not improved, by undertaking urgent reduction, rather than waiting for ENT specialist care a few days after the injury." (Personal correspondence with the Medical Defence Union).

My search for what is accepted practice for "on the spot" treatment of nasal fractures proved fruitless!

In conclusion, I think that until "What is accepted practice for sports medicine doctors" is tested in a court of law, we are still left with no straight answer to the question. In simple terms, individual doctors must ask themselves whether they are competent to undertake the procedure.

First aiders are covered by the Good Samaritan Act of $1983^{1}$ to administer first aid according to the accepted practices and manuals of the voluntary first aid societies; this does not include reducing nasal fractures.

JANE DUNBAR Dunblane, Scotland 